\title{
Viewpoint: \\ The rangeland condition concept and range sci- ence's search for identity: A systems viewpoint
}

\author{
DAVID L. SCARNECCHIA
}

\author{
Author is associate professor, Department of Natural Resource Sciences, Washington State University, Pullman 99164 - \\ 6410 .
}

\begin{abstract}
This paper analyzes the rangeland condition concept, and discusses how the search for a general concept has been part of the larger search for the identity of range science. It distinguishes between the concept and the assessment of rangeland condition, and distinguishes between the concept and ecological theories used in condition assessment. It proposes a general condition concept of modular character in which different ecological theories and field data are interchangeable components applied locally on appropriate, specific areas. It discusses past distinctions between range management and range science, implores the development of range management science, and discusses efforts needed in research, education, and administration to pursue its development. It interprets past and current events related to range science, including the advent of rangeland health, and discusses their relationships to range science's unfulfilled development as a management science. The paper encourages systematic design of concepts needed to allow range science to fulfill its philosophical potential as a management science.
\end{abstract}

Key Words: rangeland health, range management, rangeland trend

This paper is in part a techno-philosophical analysis of the rangeland condition concept. But the paper goes beyond rangeland condition to examine how the search for a rangeland condition concept has been part of the larger search for the identity of range science. It begins by distinguishing between the rangeland condition concept per se and the ecological theories used in condition assessment. It explores how inadequate conceptualization of rangeland condition and other range science concepts has produced a range science of weak identity. The paper implores systematic conceptual design. It supports the development of range science as a management science. It interprets past and current events related to range science, including the advent of rangeland health, and discusses their relationships to range science's unfulfilled potential as a management science. The paper discusses efforts needed in research, education and administration to pursue

\footnotetext{
The author thanks Dr. Grant Harris, Dr. Ben Roche, Cindy Roche, and Ray Richmond for helpful comments concerning the manuscript. Manuscript accepted 1 Oct. 1994.
}

development of range management science. It is written as a Viewpoint paper, so philosophical and stylistic latitude are requested. The discussion begins with range condition, addresses a network of matters related to range management science, then returns to range condition, with the goal of edifying both the concept and the science.

\section{The Rangeland Condition Concept-Objectives}

Failure to conceptually isolate the concept of range condition from ecological theory has caused inevitable frustration, and has produced conceptual inadequacies summarized by Risser (1989), Smith (1989), and others. The rangeland condition concept should be conceptualized as a tool (Scarnecchia, 1991) to apply ecological theory in rangeland assessment. This conceptualization requires that the range condition concept itself not be an ecological theory, and more specifically, that the concept per se be devoid and independent of any ecological theory, including theories involving succession, climax, stable states, and threshholds. A general, adaptable range condition concept must be designed to apply, but not consist of, regionally applicable, partially validated, ever-evolving ecological theories.

Isolation of the concept can be accomplished by limiting the concept of range condition to an objective function. This objective function could take the form of an objective-based, decisionaiding model, i.e., an expert system, serviced by appropriate ecological theories utilizing ecological data. An application of such an approach is described by Bosch and Booysen (1992). Range condition becomes only a weighted function of a group of variables representing values considered important on rangelands. Range condition assessment takes on a modular character as ecological theories (submodels) become interchangeable components. Data sets become interchangeable modules as well. The range condition concept (model) can then have a fixed structure in which individual variables can be added, removed, emphasized or deemphasized through its weighting function and parameters. The concept per se, whether no more than a weighted function of a few variables, or a sophisticated expert system, can have its own identity apart from evolving ecological theories. It becomes purely integrative, a distinctly interpretive part of the management science of range science. The concept now has the advantage of heuristic design, so that it can accomodate ever-increasing ecological data and evolving or regional theories by modular sub- 
stitution without loss of identity. If desired, the condition model can be easily modified to accomodate changing social values, but the character of the concept remains intact.

\section{Confounded Concepts-Some Symptons}

As explained, the advantages of defining the range condition concept as an integrative concept independent of ecological theory are clear. But nearly all papers on range condition, both early and recent, grapple with limitations of ecological theory and data which are properly peripheral or even irrelevant to a welldesigned range condition concept. Most papers have not distinguished between the range condition concept and range condition assessment. They have not distinguished between ecological theories and a range science concept. The rangeland condition concept has been confounded. Rangeland researchers, working with specialized objectives, have often integrated (and confounded) within concepts rather than integrating concepts within applications. Many concepts have developed unsystematically, with ad hoc integration passing for systematic, unconfounded design based on multiple objectives. The problem has been acute in the case of rangeland condition, but has characterized many other range science concepts.

The inadequacy of range science concepts is sufficiently pervasive that range science per se seems to be dying a slow death. As the range management discipline has recently experienced declining political fortunes in public lands issues, range science, to the extent it can be identified, has been scrutinized. Meanwhile, the name range science has been disappearing from department names at our academic institutions. In 1991 the Range Science Department at Texas A\&M University was renamed the Department of Rangeland Ecology and Management. The Range Science Department at Utah State University has been renamed the Department of Rangeland Resources. In the latter case, management preferences of undergraduate students, and a desire to emphasize the land helped motivate the change, as did the perception that the name range science inadequately addressed the social dimensions of range management (See Fig. 1). But the Department Head (J.C. Malechek, personal comm.) confided that few could agree on what range science really was.

These name changes can offhandedly be explained as simple politics and economics, but the identity problem of range science is more profound than politics. The explanation is better transposed to assert that the political and economic disenfranchisement of range science reflects the failure of range science to establish credibility as a distinct science worthy of political and economic support.

If range science were simply a technical science directed at a low value resource, the loss of the science might be acceptable. But of the land management sciences, range science has been conceived as a broadly-based, integrative science, integrating more technical sciences such as forest science, hydrology, wildlife biology, sociology, ecology, and others (Fig 1.) Its technical, conceptual development has never approached its philosophical potential. Nonetheless, range scientists have often been recognized as good interdisciplinary scientists, and good natural resource administrators, due largely to their integrative philosophical backgrounds, rather than to any technical training in the analysis of complex systems. The shortage of technical expertise in systems analysis among researchers in forestry, animal sciences, wildlife biology, and even ecology has hindered development of these sciences, but the longer histories of these sciences, their economic constituencies, and institutional inertia have helped maintain their integrities.

\section{Other Symptons-Enter a Stranger}

The marketing success and staying power of the Savory Grazing Method, later to become Holistic Resource Management (Savory 1988) are partly attributable to the unfulfilled technical development of range management science. Based on the philosophy of Jan Smuts and the grazing principles of Voisin, this information product, purportedly inspired by simple observation of the African bush (Savory 1988), has many analogues in the information marketplace. Most such promotions practice information arbitrage, exploiting knowledge-gap or communication niches between science and management. Some, such as schools or institutions of holistic medicine, have developed by presenting a systems philosophy in the face of a formidable, institutionally entrenched, technically developed science.

To Holistic Resource Management, range science has been a less formidable adversary. Allan Savory incrementally observed that range management involved complex, synergetic, "holistic" systems. With the management science (range science) yet primordial, it was necessary only for him to enunciate (reenunciate, see Fig 1.) the basic systems principles of range management, without undertaking any substantive and challenging holistic science. Real holistic management (beyond art) involving rangelands is not possible without an holistic range science, but it has mattered little. With some exceptions, Savory was well received. He reminded us who we were. With holistic rhetoric, he has disparaged the technical development of range management science. But that probably has not mattered much either, because range scientists and educators have never been anxious to develop their management science beyond philosophical generalities. To paraphrase G.K. Chesterton, range science "was not tried and found wanting, it was found difficult and not tried." Without a developed range science, range management has proven disoriented, easy prey for airy philosophical predators. Now that is a principle that can be inspired by simple observation of the African bush.

\section{Management, Art, Science and Management Science}

Range science has never developed significantly as a management science. But much energy has been spent philosophizing about the distinction between range management and range science. Recently, Provenza (1992) characterized them as complementary but distinct endeavors, citing Stoddart, Smith, and Box (1975), who characterized range management as an attempt to optimize returns from rangelands in combinations desired by and suitable for society through the manipulation of range ecosystems. Provenza went on to say that as such, "range management is a planning process, in which alternative management options are exposed to the decision maker's values, and the option with the highest value is selected." The unmade distinction is whether the "optimization" and "planning" are informal, mental analyses (i.e. art) or formal systems analyses (i.e., science). If range science is substituted for range management in the characterizations cited above, the results are good characterizations of range sci- 
ence as a management science. The original descriptions cited lump all optimization and planning analyses into range management. This long-standing placement has been, and still is hindering the development of range science, because not only are multiobjective, multi-variable optimization, interaction and planning concepts, and analyses (beyond experiential art) a part of range science, they are the core of range science.

At least, they seem the only core, the only distinct identity, that range science can have. That identity involves range science concepts like range condition in the core area of Fig. 2. These concepts are the basic tools used to operate across Boundary A and then within the mantle of Fig 2. Quantitatively, these concepts can take the form of simple independent variables, to complex dependent variables, to complex functions of core variables, to analytical models and expert systems. The core includes rigorously defined and limited concepts such as animal-unit equivalents (Scarnecchia and Gaskins 1987), stocking variables and other interactive variables, palatability, preference, species substitution ratios, carrying capacity (Scarnecchia, 1990), harvest and production efficiencies, range condition, range trend, and the myriad other concepts and variables, including many not yet conceived (Scarnecchia 1994). Many such concepts of range management science should be designed to link ecosystem components for multi-objective management. The opportunity to develop the sys- tematic core concepts is itself immense, and the challenge of developing analytical models, and appropriate field research applying them within the mantle of range science is still greater.

The mantle area graphically represents where range economists, range wildlife scientists, range ecologists, and the other combinations of Fig. 2 have conducted most of the research conventionally termed range science. The undeveloped core represents the management science-not simple components of rangelands, but basic core concepts like range condition which give range science its identity. Maybe the presence of this core, and the identity of range science as a management science were implicit in Fig. 1. The literature cited in the first paragraph of this section suggest that the idea, if implied, was not received.

\section{About Education}

Range science as a management science has been difficult to face. Most range scientists are not trained to deal with range science as a management science. Most scientists who consider themselves range scientists work on plant ecology, hydrology, animal science, fire ecology, wildlife biology, etc. on rangelands. Like many specialists in these other sciences, they often have little conceptual or technical education in systems analysis. What training exists is often intellectually discrete from their mainstream disciplinary knowledge, much as range modeling research

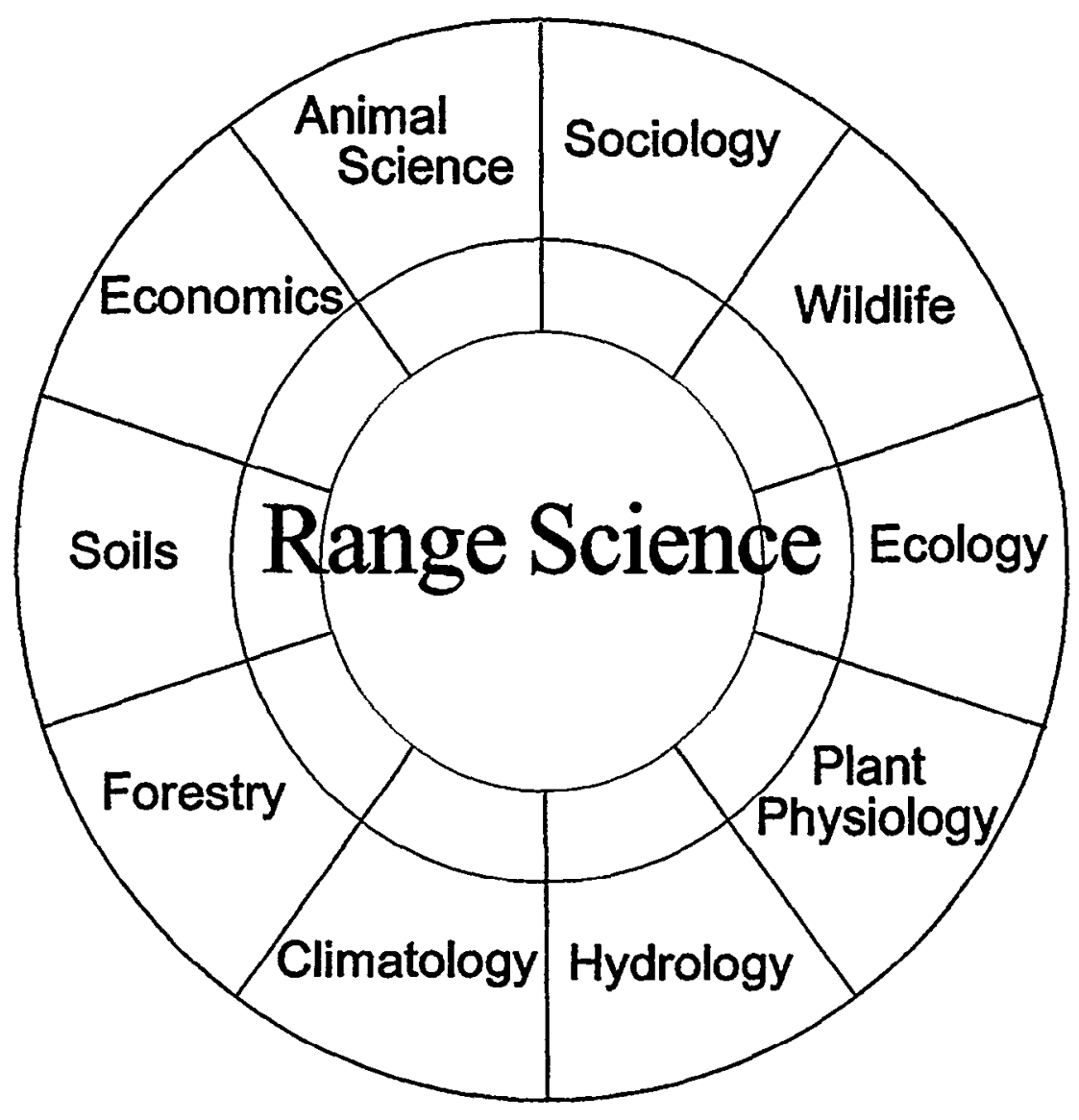

Fig. 1. Range science and its supporting sciences as conceived twenty years ago, and as widely taught since then. Reproduced from Stoddart, Smith, and Box (1975). 


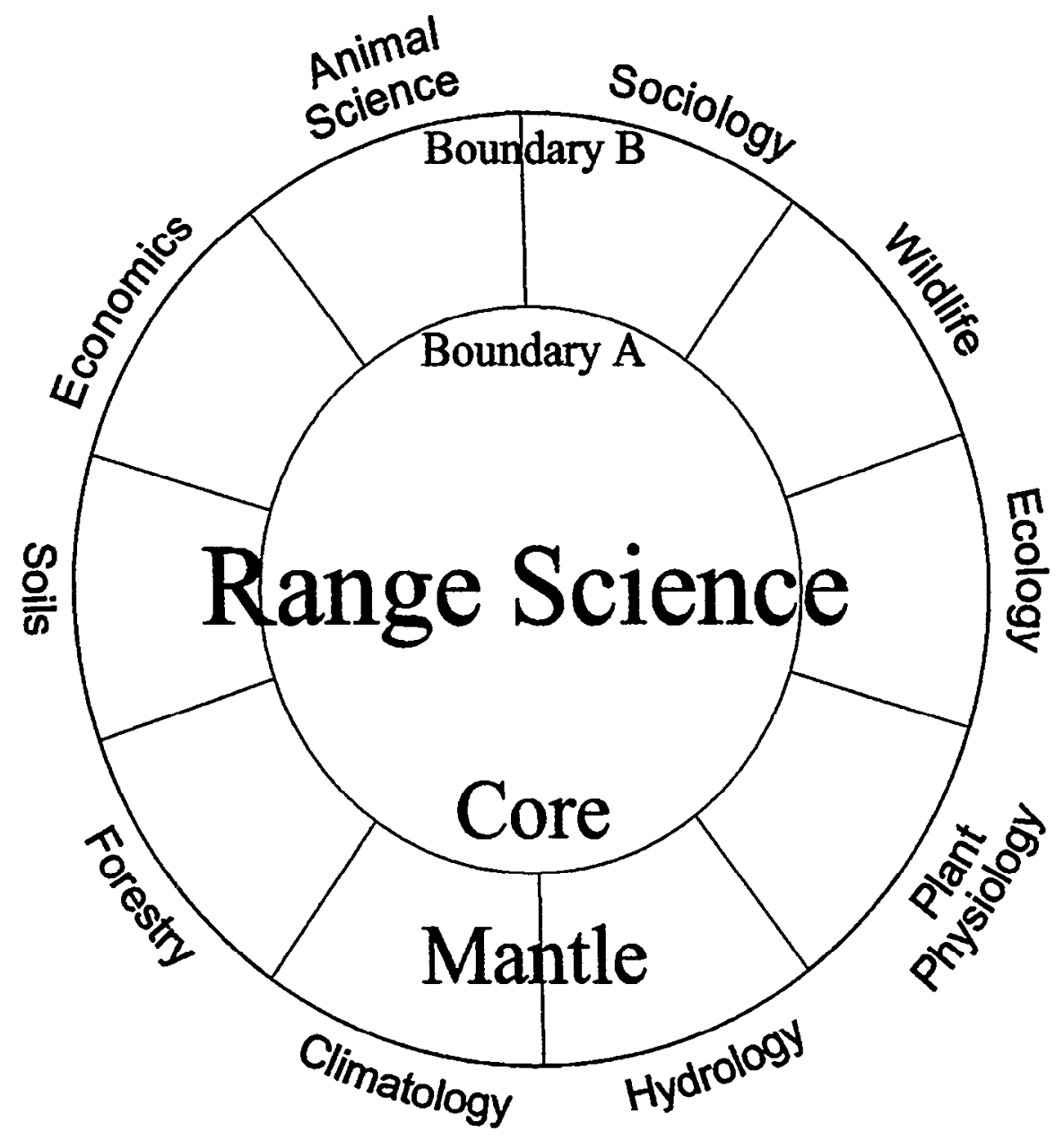

Fig. 2. Adaptation of Fig. 1. showing conceptual core, mantle and boundaries of range science as a management science. The core of range science, consisting of systematically designed concepts and models relating them remains largely undeveloped.

is tacitly isolated from range science proper.

Most university range science departments have better addressed the development of range management than range science. The encouragement to do so has come from several sources. Often our range science departments are in land grant universities, where a management mission has been emphasized. Some undergraduate students in these departments are refugees from quantitative sciences; many enter range management programs with the idea that the analytical demands on them will be fewer than in other fields. Some undergraduates have little interest in science and come only to study what they see as applied management. Often these students come from rural backgrounds where economic pragmatism and local culture foster a desire to learn management without learning science.

Most graduate education in range science provides little training in range science as a management science. Because Ph.D. level researchers and professors in range science frequently have little systems training, and because retraining possibilities are inhibited by institutional constraints (tenure, etc.), the unfulfilled potential and future of range science may be in the hands of the next generation of range scientists. Future-thinking programs with a long-term interest in range science need to begin educating their graduate students in the technical, analytical methods need- ed to analyze complex systems so that they can effectively apply basic physical, chemical, and biological sciences. This redirection will involve more than adding an isolated course or 2 in systems analysis to graduate programs. It will involve redirecting some program efforts toward the philosophical, conceptual, and technical design of range science, based on principles of multi-objective, multi-variable analysis of systems. But because this range science core has never developed, research will be needed.

\section{About Research, Funding and Publication}

Future concepts within range science will need to be designed with a strong sense of general applicability. Concepts will need to be rigorously limited in content so that they can be used to describe unconfounded relationships among many variables. Some concepts, such as range condition, are best designed to be compatible with modular components while remaining conceptually intact themselves. Research institutions interested in range science will need to direct research efforts at these design-integration problems.

Such research will likely require less research funding than traditional field research, but it will require more creativity of researchers. Supporting field research should be gradually reoriented toward the more systematic structure of the evolving range 
science. Internal and external funding sources will need to recognize the value of conceptual design research, and support it. It should be given at least equal weight with traditional range research, some of which has produced little of lasting value.

Publication of such research will require support of journals such as the Journal of Range Management. The Journal could reconsider becoming the Journal of Range Science, even though a recent opinion poll favored retention of the Journal of Range Management. The name Journal of Range Management Science is worth considering. It could consider adding 1 or 2 philosophically oriented systems analysts as associate editors. Currently, dataless papers on conceptual design are given second-class consideration with opinion papers on policy, etc. as Viewpoint papers, even though conceptual work is a bottleneck in range science development. Generally, the Journal could support the development of range management science by becoming more of a forum for technical discussion of range science concepts-not just topical ones like range condition, but other systematically designed range science concepts, approaches and models. And individual researchers who develop concepts in their modeling work will need to be more effective in explaining their ideas in simple language to allow their evaluation and possible adoption within the mainstream of range science.

\section{About Leadership}

In 1961, Forrester wrote that "thus far, management science has still not penetrated the inner circle of top management ." Thirtythree years later, this statement still applies to range science. Building range science, the management science, will require leadership, preferably by individuals in influential positions. Too often individuals currently in range science administration have abandoned their roles as scientists and pursued political challenges rather than the challenge of developing range science.

Young entry-level scientists apparently have received the message; success in obtaining research funding and in political networking are better rewarded than technical efforts at developing range science. So young scientists, many lacking systems skills, take the obvious course.

Leadership will be needed from somewhere if range science is to fulfill the potential of its philosophy, and survive as an integrative land management science. Its survival is important as a central science among the more technical, factional resource sciences. Also, range management will likely not prosper as a distinct discipline without a conceptually adequate range science.

\section{Range Condition Again}

Developing an effective range condition concept is basic in developing range science, the management science. The range condition concept is properly in the core (Fig. 2) of range science, while the process of range condition assessment involves the core, mantle, and supporting sciences, linking the concept with ecological theories and ecological data outside the mantle for area-specific assessment. This distinction allows the concept to have a clean, universal identity as a multi-objective function or model, without having it confounded with the theories it is designed to apply. Unlike many other core concepts (e.g., stocking variables), range condition is a kind of terminal concept in that it is not likely to be used in more complex models where subsequent mathematical confounding (Scarnecchia 1988) with other variables would be a problem.

We need to design a universal rangeland condition concept. This activity is much simpler than misdirected attempts to develop a universally applicable approach to rangeland condition assessment. Recently, the Task Group on Unity in Concepts and Terminology of the Society for Range Management (1991) "has tried to follow a course of developing an approach to 'Range condition' assessment which accommodates modern viewpoints of the nature of vegetation changes, but is not excessively dependent on the correctness of any of them." The quotation marks around range condition belong to the Task Group, and they suggest that the groùp had so nebulous an idea about what the range condition concept per se is that they were uncomfortable using the term without placing it in undirected quotation marks, "you know."

Foran et al. (1986) stated that "the philosophical concepts which form the basis of range condition assessment are now in a period of considerable ferment and change." As long as theoretical and community ecologists exist this observation will remain valid. Joyce (1992), drawing little distinction between concept and assessment of range condition, speculated that innovation will require emergence of a single transcendent ecological theory linked to an equally inspired field method. This scenario, the emergence of a unifying ecological theory and a multi-dimensional field method adequate to assess it, would be a miracleactually a compound miracle. It will not happen any time soon. For this reason, we need a discrete range condition concept which can accomodate evolving general or area-specific theories. Then range condition will not need to be placed in vague quotation marks. We will have a concept which can be applied universally, and a dynamic, modular, assessment capability which can be applied locally.

Recently, the National Research Council (NRC) (1994) has promulgated the concept of rangeland health based on the "integrity" of the soil and the ecosystem processes on rangeland. This approach willingly abandons the conceptual weaknesses and socio-political baggage (e.g., "fair", "poor", etc.) of rangeland condition, embracing the profound but inscrutable ecological processes of ecosystem management. The historically unfettered term rangeland health is as comfortably familiar as it is conceptually imprecise. From sentence one, the NRC (1994) definition that "Rangeland health should be defined as the degree to which the integrity of the soil and the ecological processes of rangeland ecosystems are sustained" leaves unclear whether rangeland health is a state or rate concept (variable), i.e., it combines and confounds the old concepts of rangeland condition and rangeland trend. Clearly this committee effort is not the unconfounded conceptual design which this paper implores.

Range scientists have long understood that ecosystem processes, while difficult to assess, are the functional essence of rangelands. Most of the early methods of rangeland condition assessment explicitly or implicitly used plant community variables or simple soil variables as measurable indicators of the extent of these processes on rangelands. Evaluation of these elusive underlying ecosystem processes may be the objective of the unifying "ecological theory tied to a field method" envisioned by Joyce (1992). In any case, the concept of rangeland health is neither a 
needed systematic step backwards in conceptual design, nor a practical step forward in rangeland assessment. It is a change in terminology without a change in conceptuality-a confounding step sideways out of the line of fire. The challenges in conceptualizing rangeland health are the same as those of rangeland condition and trend, and based on past experience, they are unlikely to be addressed effectively by large committees concerned mostly with designing palatable terminology for communicating rangeland policy.

If they can be adequately assessed, soil integrity and basic ecosystem processes can be accommodated like other ecological theories and data within the modular range condition concept proposed in this paper. But because of our limited understanding of ecosystem processes, and for ease of measurement, the role of indicator variables in assessing these processes will remain.

\section{Much to Do}

The search for a range condition concept is part of the parallel, wider struggle to find an identity for range science. The core of range science is composed of a wealth of other concepts, which, if properly designed, can describe clear relationships in the core and mantle of Fig. 2. Much work and communication are needed to design effective, understandable core concepts. The concepts and their interactions should have minimal confounding, and be designed to describe and analyze complex relationships, and synergies in the core and mantle. These core concepts will give range science its identity, and enable it to fulfill its philosophical potential as an integrative management science. And as disciplinary boundaries gradually dissolve in the natural resource sciences, a conceptually developed management science will ensure the role range science and range scientists in future policy affecting rangelands.

To get a core of systematic concepts for range science will require focused efforts at concept design. As a bonus, welldesigned concepts may have artistic qualities such as symmetries, interchangeability, unity, and simplicity. Then range science, like this paper, will have come full circle-from a management art, to an experimental science, to a management science, and back to art again.

\section{Literature Cited}

Bosch, O. J. H., and J. Booysen. 1992. An integrative approach to rangeland condition and capability assessment. J. Range Manage. 45:116-122.

Chesterton, G. K. Reader's Digest great encyclopedic dictionary. Dictionary of quotations. Reader's Digest Assn., Pleasantville, N.Y..

Foran, B. D., G. Bastin, and K. A. Shaw. 1986. Range assessment and monitoring in arid lands: the use of classification and ordination in range survey. J. Environ. Manage. 22:67-84.

Forrester, J W. 1961. Industrial dynamics. M.I.T. Press, Cambridge, Mass.

Joyce, L. A. 1993. The life cycle of the range condition concept. J. Range Manage. 46:132-138.

National Research Council. 1994. Rangeland health. National Academy Press. Washington, D.C.

Provenza, F. D. 1991. Viewpoint: Range management and range science are complementary but distinct endeavors. J. Range Manage. 44:181-183.

Risser, P. G. 1989. Range condition analysis: past, present and future. pp. 143-156 In: W. K. Lauenroth and W. A. Laycock, eds. Secondary succession and the evaluation of rangeland condition. Westview Press, Boulder, Colo.

Savory, A. 1988. Holistic resource management. Island Press, Covelo, Calif.

Scarnecchia, D. L., and C. T. Gaskins. 1987. Modeling animal-unit- equivalents for beef cattle. Agr. Syst. 23:19-26.

Scarnecchia, D. L. 1988. Minimizing confounding in case studies of agricultural systems. Agr. Syst. 26:89-97.

Scarnecchia, D. L. 1990. Concepts of carrying capacity and substitution ratios: a systems viewpoint. J. Range Manage. 43:553-555.

Scarnecchia, D. L. 1991. Book review. Secondary succession and the evaluation of rangeland condition. J. Range Manage. 44:525.

Scarnecchia, D. L. 1994. A viewpoint: Using multiple variables as indicators in grazing research and management. J. Range Manage. 47:107-111.

Smith, E. L. 1989. Range condition and secondary succession: a critique. pp. 103-141 W. K. Lauenroth and W. A. Laycock, eds. Secondary succession and the evaluation of rangeland condition. Westview Press, Boulder, Colo.

Society for Range Management. Task Group on unity in concepts and terminology. 1991. Society for Range Management, Denver, Colo.

Stoddart, L. A., A.D. Smith and T. W. Box. 1975. Range management. McGraw-Hill Book Co., New York. 